\title{
nature
}

18/25 December 1997 Volume 390 Issue no 6661

\section{Post-Kyoto agendas}

The Kyoto meeting on climate change was a small triumph for the international community and a benchmark in the process of consensus. But much bigger challenges lie ahead, for scientists and politicians alike.

W ho emerges with most credit from the Kyoto summit? The United States has clearly gone further to achieve a deal agreeing to a 7 per cent cut in its emissions without quite securing the involvement of the developing countries in the project — than its detractors had envisaged. President Bill Clinton and Vice-President Al Gore would have taken much of the blame if the meeting had collapsed for not standing up more firmly to the fossil-fuel and automobile lobbies, and can take credit for defying the pessimists and allowing it to succeed.

The conference chairman, Raul Estrada Ouyela of Argentina, deserves congratulation for his witty and successful browbeating of delegates. Australia, India, China and Saudi Arabia deserve credit for not derailing the talks. Bouquets, too, to the Japanese hosts for picking the UK deputy prime minister, John Prescott, for a diplomatic role which he amply fulfilled, and for the fact that the agreement that emerged is close to Japan's compromise proposal.

Now for the political reverberations. A tentative agreement has been reached between the developed countries, but more work and some flexibility from the developing countries - is necessary before the next meeting of the parties in Buenos Aires next year if a full treaty is to be ratified.

As the Clinton administration attempts to prepare the ground for ratification by the US Senate, the onus will fall on scientists to convince both Senate and the wider public that scientific knowledge of climate change is sufficiently robust for the economic upheaval required to implement the targets agreed at Kyoto. Given the timetable of Clinton's implementation plan, researchers have at most five years left to do what they have not quite achieved in the past ten, and convince a wider audience in the United States that the science of global climate change represents such a foundation. Most senators - like most of the people they represent - have yet to pay enough attention to form a well-founded view on the matter.

Over the next few years, some of the toughest scientific challenges will be in the areas of emissions measurements, verification and regional impacts. A new report issued last week by the Intergovernmental Panel on Climate Change, The Regional Impacts of Climate Change, does a useful job in spelling out regional, ecological and hydrological sensitivities to global warming. But it is also clear that several years, at least, of development of models and computing will be required before regional predictions can inspire confidence.

It is salutary to realize that, all else being equal, whatever was agreed at Kyoto could make only a small and undetectable fraction of a degree difference in the average temperature in 2100. That makes Kyoto's achievements important more as a concentrator of minds. And Kyoto suggests that a top-down approach to emissions reduction, even with more determination on all sides, will never be sufficiently effective to yield the scale of reductions that models suggest is required. But it is questionable whether market forces will also contribute much, even if energy prices were to rise. Even where there is a clear and immediate threat, such as malaria, the combined forces of politics, education and business have proved thoroughly inadequate in alleviating the problem.

If the developed countries are serious about meeting the targets they have set for themselves - and readers should note that the summit delivered no penalties for overshooting — they will encourage very considerable additional public and private sector investments in the research and development of new energy sources and energy conservation techniques. One of Kyoto's achievements is to have highlighted the need to go much further in that direction than is at present envisaged.

\section{World wide wastrels?}

\section{The Internet has aggravated a problem with youthful interest, but also provides a solution.}

Y ou know that feeling of resentment. Some kid somewhere or worse, some undergraduate — writes you a letter asking vaguely for help with a science project related, more or less, to your field of research. What to do? Curse and ignore? Mutter "don't they teach them to use libraries any more?" and reply with a peremptory instruction not to be so lazy? Nowadays, of course, letters have been superseded by e-mails. Thanks to the Internet and the World Wide Web, such 'cold calling' by total strangers is all the more frequent. And it's not as if they are your own offspring, to whom you might respond in the patient, considerate and generous manner that reflects the real you.

Malcolm Buck, a geologist at the University of New South Wales (m.buck@unsw.edu.au), was sufficiently provoked by one polite but all-encompassing request about volcanoes ("If you could please e-mail me with any information on the [nine] topics listed...") to undertake a survey of how other Earth scientists are dealing with this growing burden.
Almost all of the 74 respondents - from nine countries agreed that a reply of some kind is necessary, but rightly concluded that one should avoid doing the student's work for him or her. A generalized reply, offering encouragement and recommending useful sources of information (including the local reference librarian), seems to be best. But recommending books is problematic, as many school and town libraries have inadequate collections.

Fortunately, help is at hand in the shape of the very monster that exacerbated the problem — the World Wide Web. Volcanology is blessed with many excellent web sites, including some with near-realtime information on erupting volcanoes. Other disciplines may be less cyberspatially well endowed, but with minimal effort - often simply a form response - scientists can direct students to sources of information that can turn a casual enquiry into an adventure. Better that than to miss an opportunity to foster scientifically minded enthusiasm. 